Www.jmscr.igmpublication.org

Impact Factor (SJIF): 6.379

Index Copernicus Value: 79.54

ISSN (e)-2347-176x ISSN (p) 2455-0450

crossrefDOI: https://dx.doi.org/10.18535/jmscr/v6i10.67

Journal Of Medical Science And Clinical Research

IGM Publication

An official Publication of IGM Publication

\title{
A Study to Assess the Knowledge of Antenatal Mothers Regarding Polyhydramnios in Antenatal OPD at Selected Hospital Chinnakakani, Guntur District, A.P.
}

\author{
Authors
}

Polimetla Apoorva ${ }^{1}$, Uppu Jayalakshmi ${ }^{2}$

${ }^{1}$ MSc (OBG Nursing) Student, ${ }^{2}$ Associate Professor (OBG Nursing)

NRI College of Nursing, Chinnakakani, Guntur District, Andhra Pradesh, India

Email:appu.polimetla@gmail.com

\begin{abstract}
Background: The growing fetus depends entirely on mothers healthy body, for all needs. Consequently pregnant women must take steps to remain as healthy and well nourished as they possibly can. Pregnant women should take into account for health care and life style considerations. Most cases of Polyhydramnios are mild and result form a gradual build up of amniotic fluid during the second half of pregnancy. Severe Polyhydramnios develop may cause shortness of breath, preterm labor or other signs \& symptoms. Physiologically the volume of fluid increases with gestation to a maximum at 36-37 weeks. It has a number of purposes, including protecting the fetus from trauma and infection, allowing lung development of the limb and other skeletal parts.

Methodology: A Descriptive survey design was used to assess the knowledge of antenatal mothers regarding Polyhydramnios. Study was conducted among the antenatal mothers who are in the age group of 36yrs and above. Sample for this study was 150 antenatal mothers from NRI general hospital chinnakakani, Guntur district, Andhra Pradesh. Participants are selected by convinent sampling technique. Structured questinnarie is prepared with two sections i.e., Part-A consisting of questions on demographic variables and Part -B consisting the knowledge items on Polyhydrramnios. Antenatal mothers answered questinnarie on Polyhydramnios. Their responses are tabulated, organized, analysed and interpreted by using descriptive and inferential statistics.

Results: The results shows that no antenatal mother is having adequate knowledge, $11.33 \%$ of antenatal mothers have moderate knowledge and $88.66 \%$ of antenatal mothers have inadequate knowledge about Polyhydramnios. There is a significant association between the knowledge and past history of Polyhydramnios.

Conclusion: Over all knowledge level regarding Polyhydramnios among antenatal mothers was deficit so information module is needed which will be helpful for them to improve this knowledge.

Keywords: Polyhydramnios, Knowledge, Antenatal mothers, Hospital.
\end{abstract}

\section{Introduction}

Pregnancy is a unique, exciting and often joyous time in a woman's life, as it highlights the woman's amazing creative and nurturing powers while providing a bridge to future. Many facets of pregnancy are covered starting with the preparation and planning stages and moving through conception, fetal development, labor and delivery and postpartum stages ${ }^{[1]}$ 
Polyhydramnios is a condition in which there is an excess of liquor amnii surrounding the unborn infant. Most fetal causes are the results of decreased fluid consumption through the gastrointestinal tract. In particular any fetal anomaly that impairs swallowing fluid from contacting the absorbative surface of the small intestine may cause Polyhydramnios. ${ }^{[2]}$

Polyhydramnios more common in women who have given birth many times before than in women who are going to have their first child. It may be acute occuring over a few days or chronic occurring over a few weeks ${ }^{\text {[3] }}$

Women, in India play a vital role in producing and rearing the responsible citizens of the nation. The present and the future of any country depend on the efficiency of the women in the family. A pregnant women is responsible to support the health of her unborn baby. The growing foetus depends entirely on the mothers health for all its need $^{[1]}$ Polyhydramnios is a relatively common obstetrical complication. Major causes include maternal diabetes chromosomal disorders immunologic disease, congenital abnormalties, multiple gestations and idiopathic reasons ${ }^{[4]}$

There is increased fetal and maternal morbidity associated with Polyhydramnios spontaneous preterm labour may occur. Successful management depends up on appropriate diagnostic evaluation prolongation of the pregnancy for further fetal maturation may be achieved with timely amniocentesis ${ }^{[6]}$ Very few studies are being conducted in this area and maternal morbidity mortality also increased with Polyhydramnios. Hence the investigator felt the need to assess the knowledge of antenatal mother regarding Polyhydramnios to reduce the complications.

\section{Objectives}

1. To assess the knowledge of antenatal mothers regarding Polyhydramnios.

2. To find out the association between knowledge of antenatal mothers regarding Polyhydramnios with their selected variables.

\section{Hypotheses}

$\mathbf{H}_{1}$ : Significant association will be there between the knowledge of antenatal mothers on Polyhydramnios and their age.

$\mathbf{H}_{2}$ : There will be significant association between knowledge of antenatal mothers on Polyhydramnios and their education.

$\mathbf{H}_{3}$ : Association will be significant between knowledge of antenatal mothers on Polyhydramnios and their occupation.

$\mathbf{H}_{4}$ : There will be significant association between the knowledge of antenatal mothers on Polyhydramnios and their income.

$\mathbf{H}_{5}$ : Significant association will be there between knowledge of antenatal mothers on Polyhydramnios and theirparity.

$\mathbf{H}_{\mathbf{6}}$ : Association will be significant between knowledge of antenatal mothers on Polyhydramnios and their source of information.

$\mathbf{H}_{7}$ : Significant association will be there between the knowledge of antenatal mothers on Polyhydramnios and Past history of Polyhydramnios in their family.

\section{Methodology}

A Descriptive survey design is used to conduct the study. The study is carried out among the antenatal mothers, who are in 36 above age group in NRIGH antenatal OPD, chinakakani, Guntur district, Andhra pradesh. One fifty antenatal mothers are selected for the study using convinient sampling techinque. A structured questoinnaire with part- $\mathrm{A}$ and part- $\mathrm{B}$, is developed and used for collecting the data from the subjects. Part-A consists of seven items on demographic variables (like Age, Education, Occupation, Family Income, parity, Source of Information), part-B consists of 31 knowledge items on Polyhydramnios. The data collection is done personally by the investigator by administering the questionnaire to the study subjects during the month of December 2016. The responses of the antenatal mothers are organized and analysed by using descriptive and inferential statistics. 


\section{Statistical Analysis}

Data were entered into MS excel sheet and analysis was done by using descriptive and inferential statistics. Frequency and percentage were used to summarize the sample characteristics and for item wise analysis. Mean and Standard deviation were used to assess the knowledge mothers regarding polyhydramnios. Chi-square values computed to find out the association between knowledge of antenatal mothers on Polyhydraminos with the selected variables.

\section{Major Findings}

\section{Findings related to sample characteristics}

Out of 150 antenatal mothers $62.6 \%$ are in the age group of $18-23$ years $.28 .6 \%$ are in the age group of 24-30 years, $5.3 \%$ are below 18 years, $3.3 \%$ are between 31-35 years,none of the mothers are 36 years and above. when it comes to education majority $(21.3 \%)$ of antenatal mothers knows to read and write $20.6 \%$ have studied upto $6-10^{\text {th }}$ class, $16 \%$ have intermediate qualification, $14 \%$ of antenatal mothers have studied $1-5^{\text {th }}$ class, $14 \%$ of antenatal mothers studied graduaation, $14 \%$ of mothers studied postgraduation and above. $73.3 \%$ of mothers are housewives and $26.6 \%$ are working women. Majority (32\%) of antenatal mothers have a family income of rupees.3000/-to rupees.6000/-, $26.6 \%$ mothers have income of rupees.9000/-and above $22 \%$ of antenatal mothers have family income of less than rupees. 3000/-. 19.33\% of mothers have rupees.6000/-to 9000/-per month. $39.3 \%$ of mothers are gravida II, $34.6 \%$ are primigravida, $26 \%$ of mothers are gravida III and above .Pertaining to source of information $55.3 \%$ of antenatal mothers are getting information from health personnel. $20.6 \%$ from relatives $15.3 \%$ from friends and only $8.66 \%$ are getting from mass media When it comes to past history of information from health personnel.20.6\% from relatives $15.3 \%$ from friends and only $8.66 \%$ are getting from mass media When it comes to past history of polyhydramnios in family $80.6 \%$ of antenatal mothers have no family history and
$19.3 \%$ of mothers have past history of polyhydramnios in the family.

\section{Findings related to knowledge of antenatal mothers on polyhydramnios}

Majority (47.3\%) of antenatal mothers knew that polyhydramnios means excess amount of amniotic fluid, $58 \%$ of antenatal mothers knew that amniotic fluid is a fluid present in uterus, $40.6 \%$ of antenatal mothers knew that normal amniotic fluid volume is $800-1000 \mathrm{ml}, 29.3 \%$ of mothers knew that amniotic fluid is important during pregnancy to protect the mother and baby from injury,34.6\% of mothers knew that more than $2000 \mathrm{ml}$ of amniotic fluid present in Polyhydramnios ,24.6\% of mothers knew that maternal diabetes ,multiple pregnancy, $\mathrm{Rh}$ disease are causes of Polyhydramnios $30.6 \%$ of antenatl mothers knew that multiple pregnancy is risk factor for developing polyhydramnios .very few mothers (37.3\%) knew that rapid weight gain is common symptom for Polyhydramnios. $41.3 \%$ of mothers knew that breathlessness, edema, enlarged abdomen are clinical manifestation of Polyhydramnios ,31.3\% of mothers knew that polyhydramnios can be identified by enlarged abdomen and troubled breathing ,45.3\% of mothers knew that amniotic fluid index and ultrasonography are used to measure amniotic fluid. $38 \%$ of mothers knew that common procedure used for Polyhydramnios is amniocentesis. $22 \%$ of antenatal mothers knew that amniocentesis is performed during $22^{\text {nd }}$ and $30^{\text {th }}$ week of gestational age. $43.3 \%$ of mothers knew that amniocentesis means taking sample of fluid from uterus.35.3\% of mothers knew that when baby moving less than usual should contact health care provider in polyhydramnios. $31.3 \%$ of mothers knew that immediate care has to taken when fluid leaking from vagina $.42 \%$ of mothers are knew that premature birth can occur due to Polyhydramnios. $\quad 27.3 \% \quad$ knew that Polyhydramnios is treated by removing extra amniotic fluid. $32 \%$ of mothers knew that control diabetes is preventive measure for 
Polyhydramios.40.6\% of mothers knew that left lateral position is maintain during Polyhydramnios. $36 \%$ of mothers knew that postpartum hemorrhage is complication of
Polyhydramnios during postnatal period $38 \%$ of mothers knew that blurred vision is eye complication can occur during Polyhydramnios.

Table -1: Mean and Standard Deviation of Antenatal Mothers Based on their Knowledge with Regard to Polyhydramnios

$$
\mathrm{N}=150
$$

\begin{tabular}{|l|c|c|c|}
\hline S.No & Item & Mean (X) & $\begin{array}{c}\text { Standard } \\
\text { deviation (S.D) }\end{array}$ \\
\hline 1 & Knowledge on Polyhydramnios & 14.1 & 5.25 \\
\hline
\end{tabular}

The mean score of knowledge level was 14.1with the standard deviation 5.25.

Fig -1: knowledge level of antenatal mothers regarding polyhydramnios

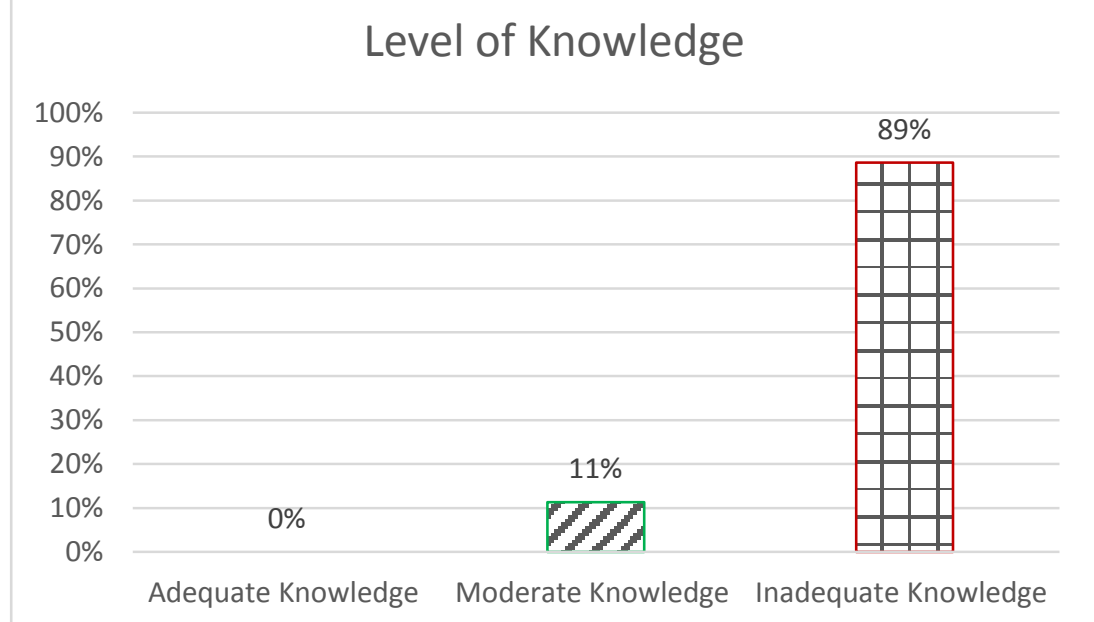

Majority (88.66\%) of antenatal mothers have inadequate knowledge, only $11.33 \%$ have moderate knowledge and none of the mothers have adequate knowledge.

Table-2: Association between Knowledge of Antenatal Mothers with Selected Demographic Variables

\begin{tabular}{|c|c|c|c|c|}
\hline S.No & Variable & $\begin{array}{c}\text { Chi-square } \\
\text { calculated value }\end{array}$ & Table Value & $\begin{array}{c}\text { Degree of } \\
\text { Freedom }\end{array}$ \\
\hline 1 & Age & $5.19^{\mathrm{NS}}$ & 15.51 & 8 \\
\hline 2 & Education & $5.19^{\mathrm{NS}}$ & 18.31 & 10 \\
\hline 3 & Occupation & $0.72^{\mathrm{NS}}$ & 5.99 & 2 \\
\hline 4 & Family income & $2.22^{\mathrm{NS}}$ & 12.99 & 6 \\
\hline 5 & Parity & $1.3^{\mathrm{NS}}$ & 9.49 & 4 \\
\hline 6 & Source of information & $4.69^{\mathrm{NS}}$ & 15.51 & 8 \\
\hline 7 & $\begin{array}{l}\text { Past history of Polyhydramnios in their family } \\
\text { in theirfamily. }\end{array}$ & $9.43^{*}$ & 5.99 & 2 \\
\hline
\end{tabular}

Note :-*Denotes significant at 0.05 level of significance

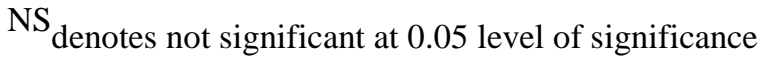

The above table denotes that significant association exist only Past history of polyhydramnios in their family and the knowledge of antenatal mothers $\left(\chi^{2}=9.43\right)$ with regard to polyhydramnios at 0.05 level of significance. No significant association is found between Age $\left(\chi^{2}=5.19\right)$, Education $\left(\chi^{2}=5.19\right)$, Occupation $\left(\chi^{2}=0.72\right)$, Family Income $\left(\chi^{2}\right.$ 
$=2.22)$, parity $\left(\chi^{2}=1.3\right)$, Source of Information $\left(\chi^{2}=4.69\right)$ and knowledge of antenatal mothers with regard to polyhydramniosat 0.05 level of significance.

\section{Discussion}

Majority of antenatal mothers (94 i.e. 62.6\%) were between the Age group of 18-23 years, followed by 43 antenatal mothers $(28.6 \%)$ were between the age group of 24-30 Years, eight $(5.3 \%)$ were in the age group of below 18 years and only five antenatal mothers were between the age group of 31-35 years. Shrutisaralaya et. al in their study reported that maximum no of mothers $(41 \%)$ were in between the age group of 21-35 years. Majority of antenatal mothers 32 $(21.3 \%)$ knows to read and write followed by $21(14 \%)_{\text {_ }}$ mothers were educated up to $1-5$ th class 21(14\%) mothers were educated up to graduation 21(14\%) antenatal mother were educated up to postagraduation 31 (20.6) mothers were educated up to 6th- 10th class only $24(16 \%)$ antenatal mother educated upto intermediate. . Majority of subjects (59 i.e. $39.3 \%$ ) are gravida - II, followed by (52 i.e. $34.6 \%$ ) are primigravida and (39 i.e. $26 \%$ ) are gravida III \& above shrutisaralaya et.al in their study also reported that $56 \%$ of antenatal mothers are multigravida. As per Source of information majority of subjects received information from health personnel (83 i.e 53.3\%) followed by (31 i.e. 20.6\%) are received information from relatives $23(15.8 \%)$ are received from friends and only 13 respondents $(8.66 \%)$ are received from mass media. In the knowledge scores out of 150 antenatal mothers most of the antenatal mothers have (133 i.e $88.6 \%$ ) inadequate knowledge followed by 17 $(11.3 \%)$ antenatal mothers who have moderate knowledge and none of the antenatal mother (0\%) having adequate knowledge regarding Polyhydamnios.

In the present study it is found that significant association is existing only between the knowledge regarding to Polydydramnios and past history of Polyhydramnios in their family at 0.05 level of significance $(\chi 2=9.43)$.No significant association was found between knowledge of antenatal mothers regarding Polyhydramnios and their age $(\chi 2=5.19)$, education $\quad(\chi 2=5.19)$, occupation $\quad(\chi 2=0.72)$, family income $(\chi 2=2.2)$, parity $(\chi 2=1.3)$ and source of information $(\chi 2=4.69)$.Over all knowledge level regarding Polyhydramnios among antenatal mothers was deficit so information module is needed which will be helpful for them to improve this knowledge.

\section{Conclusion}

Study concluded that majority of respondents had Inadequate knowledge on Polyhydramnios. The knowledge of Antenatal mother regarding Polyhydramnios is significantly influenced by Past history of Polyhydramnios. There is no association between the knowledge of antenatal mothers regarding Polyhydramnios and Variables of Age, Education, Occupation, Family income, Parity, Source of information and Past history of Polyhydramnios.

\section{Acknowledgement}

We acknowledge mothers for their cooperation and participation in sharing their information regarding polyhydramnios.

\section{References}

1. Jessica Evert. Introducton To Pregnancy, 2005, August12.

2. Paver HU Fetal malformations in pregnancies complicated nbyoligo and polyhydramnios :2014;18(2)

3. Mayo Clinic Staff, Diseases And Conditions Of Polyhydramnios Oct,2014.

4. Minakshi Rohilla, Paul Arora, Vanita Jain, Idiopathic Polyhydramnios, 2016, July 2016,5:183

5. Ignou ,Text Book Of Medical And Surgical Nursing School Of Health Sciences New Central Book Agents ,4th Edition ,New Delhi, 1997. 
6. Wikipedia: Polyhydramnios Symptoms Causes And Treatment;

7. Major M, GhezziI, Maymon E. Polyhydramnios Is An Independent Risk Factor For Perinatal Mortality And Intrapartum Morbidity In Preterm Delivery .1996Dec;70(1):41

8. Lallar Meenakshi, Annamul Haq, Nanda Rajesh, Perinatal Outcome In Idiopathic Polyhydranios Federation Of Obstetrics And Gynaecological Society Of India,2015;65(5),310-314.

9. Kaukab Tashfeen And Ilham Moosa, Hamdi Polyhydramnios As A Predictor Of Adver Se Pregnancy Outcomes, Sultan Qaboos University ,MedJ,2013;13:57-62.

10. Odibo IN, Newville TM. Idiopathic Polyhydramnios. Peersistence Across Gestation And Impact On Pregnancy Outcomes. 2016:Apr, 199:175-8.

11. Ron Belooskey, Md Et Al, Polyhydramnios, 2017.

12. Luo QQ, Zheng. Idiopathic Polyhydramnios At Term And Pregnancy Outcomes: In Selected Hospitals, China.2016,Sep14:1-5.

13. Boito S, Crovetto, Ischia, Prenatal Ultrasound Factors And Genetic Disorders In Pregnancies Complicated By Polyhydramnios. 2016, Aug:36(8); 726-30

14. Karahangolu E, Ozdemiricis. Intrapartum, Postpartum Characterstics And Early Neonatal Of Idiopathic Polyhydramnios.2016 Aug;36(6):710-714.

15. LIU LL, Pang LH, Deng BY. Prenatal Diagnosis And Pregnancy Outcome Analysis Of Polyhydramnios.2016 Dec;35(1):21-8.

16. Piliod RA, Page JM, Burwick RM. The Risk Of Fetal Death In Non Anamolous Pregnancies Affected By Polyhydramnios. Boston.2015 Sep;213(3);410.

17. Aviram A, Salzer L. Association Of Isolated Polyhydramnios At Or Beyond 34
Weeks Of Gestation Aand Outcome. Petah Tikva, 2015Apr;125(4):825-32.

18. Abdalla N, Bachanek. Placental Tumor Chorioangioma) As A Cause Of Polyhydramnios. Poland 2014 Nov;20;955-9.

19. Dickinson JE, Tjioe YY, Jude E. Amnio Reduction In The Management Of Polyhydramnios Complicating Singleton Pregnancies .Australia 2014, Oct: 211(4);434.

20. Hamzaa, Herrd, Solomyer. Polyhydramnios: Causes, Diagnosis, Therapy. Hombrug/ Saar.2013 Dec;73 (12);1241-1246. 